\title{
ESTADO ENERGÉTICO DA ÁGUA NA GERMINAÇÃO DE SEMENTE DE SOJA ${ }^{1}$
}

\author{
FRANCISCO AMARAL VILLELA ${ }^{2,4}$, ANADIONISIADALUZCOELHONOVEMBRE ${ }^{3}$, JULIO MARCOS FILHO ${ }^{3,4}$
}

\begin{abstract}
RESUMO- O potencial hídrico da semente ou de suas estruturas pode indicar, de maneira mais consistente, o estado energético da água na semente, comparativamente ao teor de água. Nesta pesquisa, desenvolvida com o objetivo de estudar as modificações do estado energético da água no processo de germinação da semente de soja, foram utilizados dois cultivares (BRS-157 e BRS132), cada um representado por dois lotes com diferentes potenciais fisiológicos. A marcha de absorção de água da semente, de suas partes constituintes (cotilédones e eixo embrionário) e o monitoramento periódico do potencial hídrico do eixo embrionário foram conduzidos sob condições de plena disponibilidade hídrica. Os graus de umidade foram obtidos pela pesagem de 100 sementes e, nos eixos embrionários e cotilédones, avaliados pelo método da estufa $\left(105 \pm 3^{\circ} \mathrm{C} / 24 \mathrm{~h}\right)$. Os potenciais hídricos dos eixos embrionários foram determinados através de psicrômetro termopar, operando no método do ponto de orvalho. O eixo embrionário absorve água com velocidade superior à dos cotilédones e atinge teores de água mais elevados durante a germinação. No momento da protrusão da raiz primária, o potencial hídrico do eixo embrionário apresenta valores similares entre cultivares e lotes, indicando que o estado energético da água no eixo embrionário está relacionado com a germinação.
\end{abstract}

Termos para indexação: Glycine max, embebição, potencial hídrico, vigor

\section{WATER STATUS OF SOYBEAN SEED DURING GERMINATION}

\begin{abstract}
The water potential of the seed or seed parts provides a better indicator of the seed water status than water concentration. This study examined the imbibition process and the water status of soybean seed and embryonic axis during seed germination. Two soybean seed lots, cultivars BRS-157 and BRS-132, were tested. Seeds were hydrated between six layers of paper towel, inside a plastic box, at $25^{\circ} \mathrm{C}$. Seed moisture content was determined by weighting samples of 100 seeds each during warter uptake process and, for embryonic axis and cotyledons, by the oven method $\left(105 \pm 3^{\circ} \mathrm{C} / 24 \mathrm{~h}\right)$. Seed water potential was measured by the hygrometric method using a thermocouple. The embryonic axis absorbs water faster than the cotyledons and reaches higher moisture content during germination. At the moment of the radicle protrusion the water potential of the embryonic axis is unique, independently of seed cultivar and physiological potential.
\end{abstract}

Index terms: Glycine max, imbibition, water potential, vigor

\section{INTRODUÇÃO}

A hidratação da semente madura, ocasiona reativação do sistema metabólico existente, suplementado pela síntese de novos compostos, que levam à divisão e à expansão celular (Labouriau, 1983; Kermode, 1995), na ausência de dormência,

\footnotetext{
${ }^{1}$ Submetido em 05/03/2006. Aceito para publicação em 15/01/2007. Parte do Programa de Pós-Doutorado do primeiro autor.

${ }^{2}$ Depto. de Fitotecnia - UFPel/FAEM, C.P. 354 - CEP: 96010-900 -
} Pelotas, RS. culminando com a retomada do crescimento do embrião e a protrusão da raiz primária.

Os programas de expressão gênica, de síntese, a sensibilidade ao ácido abscísico e as relações hídricas estão intrinsecamente relacionados em diferentes processos bioquímicos e fisiológicos da planta, inclusive no

\footnotetext{
${ }^{3}$ Depto. de Produção Vegetal - USP/ESALQ, C.P. 09 - CEP: 13418-900 Piracicaba, SP.

${ }^{4}$ Bolsista CNPq.
} 
desenvolvimento e germinação da semente (Kermode, 1995; Villela, 1998). Assim, as modificações no estado da água interferem na natureza e na cinética das reações químicas e exercem influência no desenvolvimento e na germinação da semente, sobretudo durante seus estádios críticos (Egli e TeKrony, 1993 e 1997; Westgate, 1994; Bradford, 1994; Kermode, 1995).

A seqüência de modificações no teor de água da semente vem se constituindo em parâmetro relativamente eficiente para caracterizar o desenvolvimento da semente; é empregada, com freqüência, na determinação da maturidade fisiológica. Por outro lado, no processo de germinação, a marcha da absorção da água vem sendo descrita, quase que exclusivamente, com base na determinação do teor de água da semente e interpretação de seu significado biológico. Entretanto, esse parâmetro não é adequado para indicar o estado da água nos processos fisiológicos durante o desenvolvimento e a germinação das sementes, uma vez que não fornece informações sobre seu estado energético (Villela e Marcos Filho, 1998).

O teor de água na semente representa a média da concentração dessa substância em toda a semente, embora possam existir variações entre suas estruturas (McDonald et al., 1988). O potencial hídrico da semente ou de suas estruturas, conforme Egli e TeKrony (1997), constitui indicador mais consistente do estado da água do que o teor de água (ou grau de umidade).

A disponibilidade hídrica, o teor de água inicial e o potencial fisiológico influenciam a velocidade de hidratação da semente. Rossetto et al. (1997), trabalhando com sementes de soja, constataram que, no decorrer do processo de absorção de água, a velocidade de hidratação decresceu com a redução do potencial hídrico inicial do substrato e com o aumento do teor de água inicial das sementes. Rocha et al. (1984) também verificaram em soja que as sementes de menor potencial fisiológico apresentaram maior taxa de absorção de água, após três e seis horas de hidratação, comparativamente às sementes de maior potencial fisiológico, fato atribuído ao aumento da permeabilidade do tegumento com o avanço da deterioração. Por outro lado, McDonald et al. (1988) não observaram variações quanto à marcha de absorção de água de cotilédones, em sementes de soja de alto e baixo vigor. Entretanto, detectaram diferenças acentuadas entre eixos embrionários.

A hidratação das diferentes partes da semente de soja não ocorre de maneira similar. $\mathrm{O}$ eixo embrionário absorve água com velocidade superior às demais estruturas. $\mathrm{O}$ tegumento reidrata com menor velocidade e, os cotilédones, com velocidade intermediária (McDonald et al., 1988).
Eixos embrionários apresentam teor de água mais elevado que as outras partes da semente, independentemente das condições de hidratação (substrato umedecido ou atmosfera úmida). Por outro lado, sementes com diferentes níveis de deterioração absorvem água de maneira semelhante, quando hidratadas em substrato umedecido; porém, diferenças marcantes na capacidade de absorção de água entre eixos embrionários separados dos cotilédones são observadas em condições de atmosfera úmida (McDonald et al., 1988).

O estado de energia da água na semente pode ser avaliado pelo potencial total d'água que, expresso na forma de energia por unidade de volume, apresenta dimensões de pressão (Villela et al., 1991; Villela, 1998).

O psicrômetro termopar, pela sua versatilidade, permite avaliar o estado da água em partes de planta, solo ou substâncias contendo água. Uma amostra, colocada numa pequena câmara isovolumétrica com ar, é mantida à temperatura constante; parte da água da amostra, ao evaporar, umidifica o microambiente da câmara, estabelecendo uma pressão parcial de vapor. A medida dessa pressão possibilita determinar o potencial químico da água e, desta forma, o potencial hídrico (Boyer, 1995).

Durante o processo de absorção de água o potencial hídrico do eixo embrionário, inicialmente baixo, aumenta rapidamente com a elevação do teor de água da semente. A ocorrência de potenciais hídricos similares no eixo embrionário, nas épocas da maturidade fisiológica e da protrusão da raiz primária, evidencia que o estado da água no tecido meristemático possa ter função reguladora no desenvolvimento e na germinação da semente (Westgate, 1994; Bradford, 1995; Kermode, 1995; Egli e TeKrony, 1997).

Considerando que o potencial hídrico pode expressar de maneira consistente o status da água na semente, quando comparado ao teor de água, e a carência de estudos sobre o assunto, esta pesquisa foi desenvolvida com o objetivo de estudar as modificações do estado energético da água na semente de soja, durante o processo de germinação, com ênfase no comportamento do potencial hídrico do eixo embrionário e do teor de água da semente inteira e de suas estruturas.

\section{MATERIALE MÉTODOS}

Foram utilizadas sementes de soja (Glycine max L.) dos cultivares BRS-157 e BRS-132, cada um representado por dois lotes com diferentes potenciais fisiológicos. Após a recepção, foram efetuadas a homogeneização dos lotes e a classificação das sementes em peneiras manuais, utilizando 
as de tamanho médio (retidas em peneira de perfuração oblonga, com crivos 5,2 x 19mm).

Para obter dois níveis de qualidade, cada lote foi dividido em duas partes, sendo uma (lotes 1 e A) mantida em câmara fria e seca $\left(10^{\circ} \mathrm{C}\right.$ e $45 \%$ UR) e, a outra (lotes 2 e B), em condições normais de laboratório $\left(18\right.$ a $32^{\circ} \mathrm{C}$ e 65 a $85 \%$ UR), por 90 dias.

Visando a caracterização da qualidade inicial das sementes, foram realizadas as seguintes determinações:

Grau de umidade: avaliado pelo método da estufa a $105 \pm 3^{\circ} \mathrm{C}$, durante $24 \mathrm{~h}$, utilizando duas amostras por lote (Brasil, 1992). Os resultados foram expressos, em base úmida, em g.kg ${ }^{-1}$ para cada lote.

Germinação: quatro amostras de 50 sementes para cada lote, foram semeadas em rolo de papel toalha, umedecido com um volume de água equivalente a 2,5 vezes o peso do substrato seco. $\mathrm{O}$ germinador foi regulado a $25^{\circ} \mathrm{C}$ e, as avaliações, realizadas aos 4 e 7 dias após a semeadura (Brasil, 1992).

Envelhecimento acelerado: conduzido em caixas plásticas, contendo $40 \mathrm{~mL}$ de água no fundo e uma camada uniforme de sementes dispostas sobre a superfície da tela interna, mantidas em incubadora a $41^{\circ} \mathrm{C}$, por $72 \mathrm{~h}$. Após o período de envelhecimento, quatro amostras de 50 sementes foram submetidas à germinação, conforme descrito no item b, sendo a avaliação realizada aos 4 dias após a instalação deste teste.

Condutividade elétrica: quatro amostras de 50 sementes, previamente pesadas e, a seguir, imersas em 75 $\mathrm{mL}$ de água destilada, foram mantidas em câmara a $25^{\circ} \mathrm{C}$, durante 24h. A condutividade elétrica da solução foi avaliada em condutivímetro DIGIMED CD-20 e os resultados expressos em $\mu \mathrm{S} \cdot \mathrm{cm}^{-1} \cdot \mathrm{g}^{-1}$.

Emergência das plântulas em campo: quatro amostras de 100 sementes por lote foram distribuídas em sulcos de 4 $\mathrm{m}$ de comprimento, a $5 \mathrm{~cm}$ de profundidade e cobertas com uma fina camada de terra. As avaliações foram realizadas aos 15 dias após a semeadura, determinando-se as porcentagens de emergência.

O estabelecimento da marcha de absorção de água foi realizado com quatro amostras de 100 sementes de cada lote, submetidas a hidratação sob condições de potencial hídrico nulo, pelo método do substrato úmido, de acordo com Rossetto et al. (1997). As sementes de cada amostra, previamente pesadas, foram distribuídas entre duas camadas de papel toalha, cada uma composta de seis folhas, umedecidas com volume de água equivalente a 2,5 vezes o peso do substrato seco $(20 \mathrm{~mL})$ e colocadas sobre a tela de caixas plásticas. As caixas, tampadas e contendo $40 \mathrm{~mL}$ de água, foram mantidas em germinador a $25^{\circ} \mathrm{C}$.

O grau de umidade das sementes e de suas partes (cotilédones e eixo embrionário), de cada amostra, foi monitorado periodicamente, em intervalos regulares de $3 \mathrm{~h}$ ao longo das primeiras $12 \mathrm{~h}$ e intervalos de $6 \mathrm{~h}$, entre $12 \mathrm{e} 48 \mathrm{~h}$, durante o processo de hidratação, num total de 11 momentos de avaliação, para cada lote. Os graus de umidade das sementes inteiras foram obtidos pela pesagem de 100 sementes, no transcurso do processo de hidratação. Os eixos embrionários e os cotilédones foram extraídos de 10 sementes, em sala com ambiente controlado $\left(10^{\circ} \mathrm{C}\right.$ e 85 a $90 \%$ UR) e, os graus de umidade, determinados em estufa a $105 \pm 3^{\circ} \mathrm{C}$, por $24 \mathrm{~h}$ (Brasil, 1992), sendo os resultados expressos em base úmida.

A separação das partes constituintes do embrião foi realizada com auxilio de lâmina de barbear e estilete. No primeiro momento de avaliação, as sementes foram, previamente mantidas no substrato úmido por dez minutos, para facilitar a remoção do tegumento.

O monitoramento do potencial hídrico foi conduzido periodicamente, em intervalos de $6 \mathrm{~h}$, no decorrer das primeiras $48 \mathrm{~h}$ do processo de hidratação, totalizando oito momentos de avaliação. Para essa determinação, eixos embrionários extraídos de quatro sementes, em sala com ambiente controlado $\left(10^{\circ} \mathrm{C}\right.$ e 85 a $90 \%$ UR), foram, imediatamente, mantidos em câmara de amostra C-52, por um período de $3 \mathrm{~h}$ para equilíbrio, a $25^{\circ} \mathrm{C}$. Após esse período, o potencial hídrico foi avaliado em psicrômetro termopar, operando no método de ponto de orvalho, conforme Egli e TeKrony (1993).

$\mathrm{O}$ delineamento experimental utilizado foi inteiramente casualizado, com quatro repetições, sendo os dados relativos à avaliação da absorção de água das sementes e de suas estruturas e do potencial hídrico dos eixos embrionários, durante o período de hidratação, submetidos à análise de regressão polinomial e os dados de avaliação da qualidade das sementes, comparados pelo teste de Tukey, em nível de probabilidade de $5 \%$.

\section{RESULTADOS E DISCUSSÃO}

Os dados médios relativos à avaliação da qualidade de sementes de soja, cultivares BRS-157 (lotes 1 e 2) e BRS132 (lotes A e B) mostram, para o cultivar BRS-157, a superioridade do lote 1 em relação ao lote 2, nos testes de germinação e de vigor (Tabela 1). Para o cultivar BRS-132, verifica-se a similaridade entre os lotes A e B, no teste de germinação e desempenho inferior do lote $\mathrm{B}$, em relação ao lote $\mathrm{A}$, nos testes de envelhecimento acelerado e condutividade 
TABELA 1. Dados médios obtidos para as determinações do grau

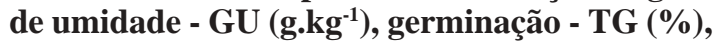
envelhecimento acelerado - EA $(\%)$, condutividade elétrica - CE $\left(\mathrm{mScm}^{-1} \cdot \mathrm{g}^{-1}\right)$, e emergência das plântulas em campo - EPC (\%) de sementes de soja, cultivares BRS-157 (lotes 1 e 2) e BRS-132 (lotes A e B).

\begin{tabular}{crrrrrr}
\hline \multirow{2}{*}{ Determinação } & \multicolumn{2}{c}{ BRS-157 } & & \multicolumn{2}{c}{ BRS-132 } \\
\cline { 2 - 3 } \cline { 5 - 6 } \cline { 5 - 6 } \cline { 5 - 6 } & Lote 1 & Lote 2 & & Lote $\mathrm{A}$ & Lote $\mathrm{B}$ \\
\hline GU & $97 \mathrm{~b}$ & $108 \mathrm{a}$ & & $93 \mathrm{~b}$ & $109 \mathrm{a}$ \\
TG & $88 \mathrm{a}$ & $73 \mathrm{~b}$ & & $95 \mathrm{a}$ & $93 \mathrm{a}$ \\
EA & $75 \mathrm{a}$ & $62 \mathrm{~b}$ & & $92 \mathrm{a}$ & $82 \mathrm{~b}$ \\
$\mathrm{CE}$ & $68,9 \mathrm{a}$ & $165,0 \mathrm{~b}$ & & $59,0 \mathrm{a}$ & $146,4 \mathrm{~b}$ \\
EPC & $71 \mathrm{a}$ & $67 \mathrm{a}$ & & $82 \mathrm{a}$ & $86 \mathrm{a}$ \\
\hline
\end{tabular}

Médias seguidas pela mesma letra na linha, para cada cultivar,não diferem entre si, pelo teste de Tukey, em nível de $5 \%$ elétrica.

Os resultados da absorção de água por eixos embrionários, cotilédones e sementes de soja, cultivares BRS157 (lotes 1 e 2) e BRS-132 (lotes A e B), mostram que semente inteira e cada estrutura funcional absorveram água de maneira semelhante ao padrão trifásico descrito por Labouriau (1983), embora não tenha havido acentuado aumento na quantidade de água absorvida, no início da Fase 3 , por cotilédones e sementes (Figuras 1 e 2).

As sementes, nas primeiras $12 \mathrm{~h}$, apresentaram rápida hidratação, atingindo teores de água próximos de $300 \mathrm{~g} \cdot \mathrm{kg}^{-1}$, ocorrendo absorção de 180 g.kg-1 (lote 2) a 225 g. $\mathrm{kg}^{-1}$ (lote A), nas primeiras $6 \mathrm{~h}$ e de 70 g. $\mathrm{kg}^{-1}$ (lote A) a 110 g. $\mathrm{kg}^{-1}$ (lote 2) entre 6 e $12 \mathrm{~h}$. Vale lembrar que, entre 6 e $12 \mathrm{~h}$, as sementes
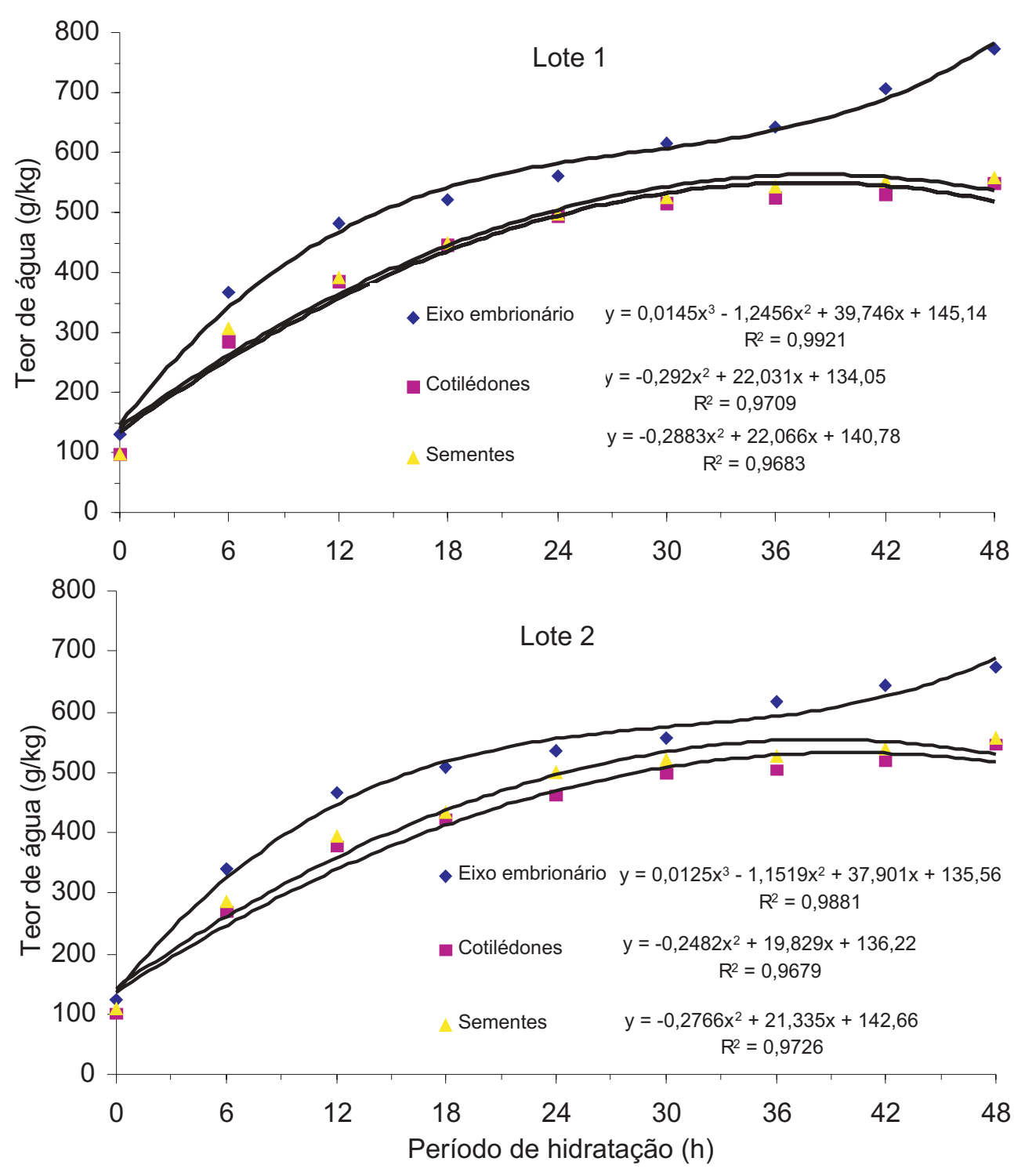

FIGURA 1. Marcha de absorção de água de eixos embrionários, cotilédones e sementes de soja, cv BRS 157 , lotes 1 e 2. 
de menor potencial fisiológico (lote 2) absorveram quantidade de água superior às dos outros lotes. A seguir, ocorreu uma fase intermediária (12 a 30h) de absorção mais lenta, até teores de água de 520 a 530 g. $\mathrm{kg}^{-1}$, suficientes para possibilitar a emissão da raiz primária. Essa constatação de que sementes onde predominam reservas cotiledonares atingem, no início do crescimento visível do eixo embrionário, teores de água de 500 a 600 g. $\mathrm{kg}^{-1}$, também foi relatada por Marcos Filho

\section{(2005) e Bradford (1994).}

Na retomada do crescimento embrionário, McDonald et al. (1988) e Egli e TeKrony (1997) observaram que as sementes de soja apresentavam, após 48 e 18h de hidratação, teores de água de 600 e 514 g. $\mathrm{kg}^{-1}$, respectivamente. Essa diferença de tempo pode ser atribuída às variações metodológicas empregadas na hidratação das sementes.

Os cotilédones não apresentaram diferenças marcantes,
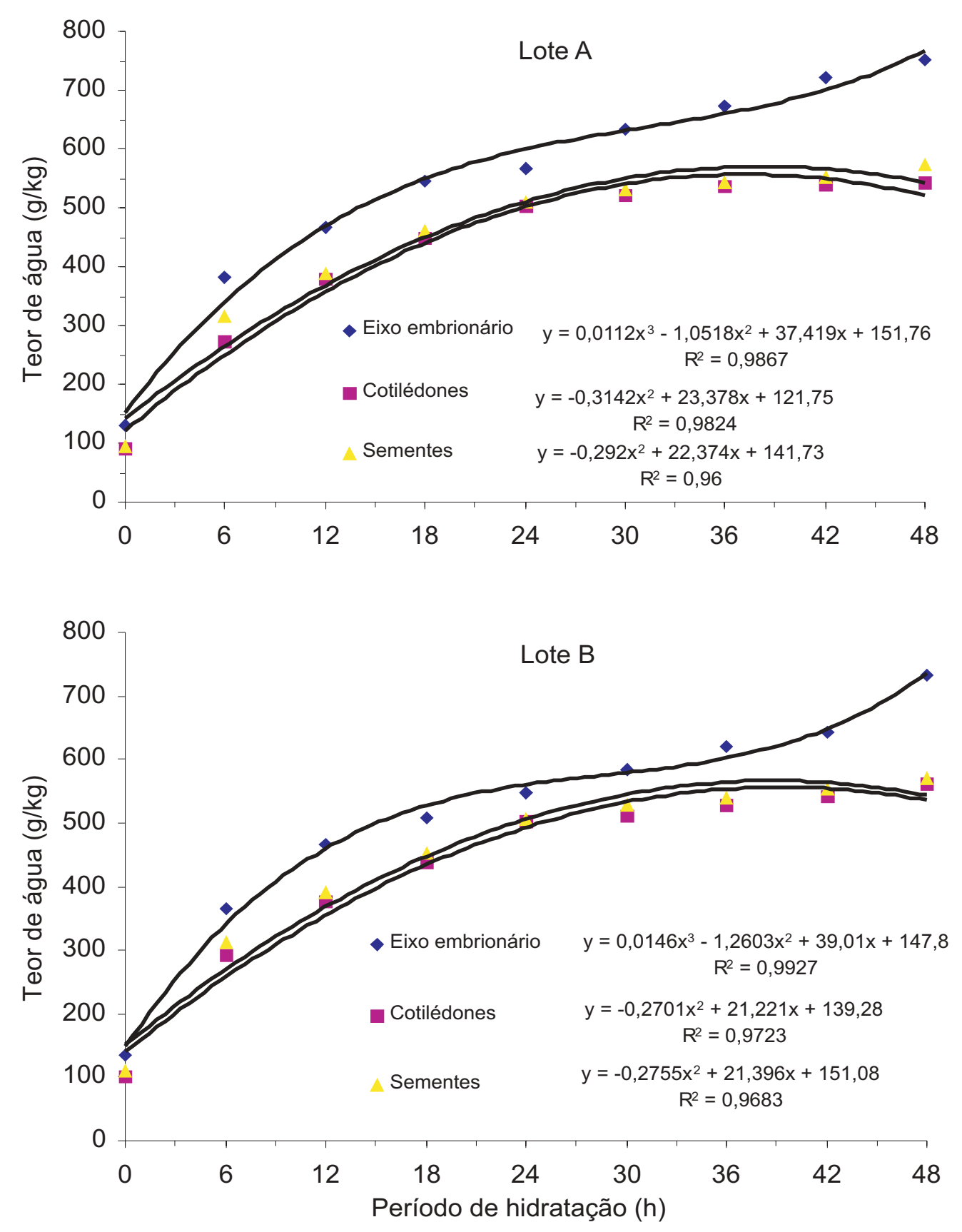

FIGURA 2. Marcha de absorção de água de eixos embrionários, cotilédones e sementes de soja, cv BRS 132, lotes A e B. 
entre lotes e entre cultivares, quanto à marcha de absorção de água. Além disso, mostraram, de um modo geral, comportamento similar ao das sementes inteiras. Essa similaridade decorre do fato dos cotilédones constituírem a maior parte, tanto da massa como do volume da semente. A massa de matéria seca dos cotilédones representa 35 a 40 vezes a do eixo embrionário.

Os eixos embrionários atingiram, no final da Fase 1, teores de água de 465 a 480 g. $\mathrm{kg}^{-1}$. A quantidade de água absorvida foi, em termos absolutos, igual à massa da matéria seca dos eixos embrionários. Na Fase 2, os lotes armazenados em câmara seca e fria, de potencial fisiológico mais alto (lotes 1 e A), apresentaram maior absorção de água (135 e 165 g. $\mathrm{kg}^{-1}$, respectivamente) em relação aos lotes mantidos em condições normais de ambiente, de potencial fisiológico mais baixo (lotes 2 e B) que absorveram 90 e 115 g. kg-1, respectivamente. Assim, após 30h de hidratação, os eixos embrionários extraídos das sementes dos lotes de maior potencial fisiológico absorveram quantidade de água aproximadamente igual a $1,8 \mathrm{vez}$ a massa da matéria seca dos eixos embrionários. Entretanto, os eixos relativos às sementes dos lotes de menor potencial fisiológico apresentaram hidratação equivalente a 1,3 vezes a sua massa de matéria seca.

Além disso, no início da Fase 3, para as sementes dos lotes 1 e A, as diferenças entre os teores de água dos eixos embrionários e dos cotilédones atingiram 100 e $110 \mathrm{~g} . \mathrm{kg}^{-1}$, enquanto, para os lotes 2 e B, essas diferenças foram de $60 \mathrm{e}$ $70 \mathrm{~g} . \mathrm{kg}^{-1}$, respectivamente.

Os lotes A (cultivar BRS-132) e 2 (cultivar BRS-157), de maior e menor potencial fisiológico, respectivamente, em relação aos demais lotes (Tabela 1), cujos eixos embrionários extraídos das sementes apresentaram, no início da emissão da raiz primária, diferencial de quantidade de água igual a 75 g. $\mathrm{kg}^{-1}$. Esses resultados confirmam as observações de McDonald et al. (1988), demonstrando que diferenças na qualidade das sementes de soja influenciam a capacidade de absorção de água de eixos embrionários. Este fato tem sido atribuído, entre outras causas, à degradação, em sementes deterioradas, de proteínas e carboidratos insolúveis, que constituem os principais compostos responsáveis pela absorção de água.

Após hidratação por $48 \mathrm{~h}$, verificou-se que os eixos embrionários das sementes do lote de menor potencial fisiológico (lote 2) apresentaram teor de água inferior aos eixos extraídos das sementes dos outros lotes.

O conjunto das informações mostrou que o eixo embrionário absorve água com velocidade superior à dos cotilédones e, também, atinge teores de água mais elevados. Por outro lado, não se verificaram, entre lotes de sementes de potenciais fisiológicos distintos, diferenças acentuadas entre cotilédones quanto à marcha de absorção de água, conforme também constadas por McDonald et al. (1988). Cabe ressaltar, todavia, a ocorrência de maiores velocidade de absorção de água na Fase 2 e teor de água na retomada do crescimento embrionário, entre eixos embrionários de sementes de soja de maior (lotes 1 e A) e menor (lotes 2 e B) potencial fisiológico.

Ocorreu similaridade, entre cultivares e entre lotes, no comportamento do potencial hídrico dos eixos embrionários, durante o período de hidratação (Figura 3). Entre 6 e 18h, ocorreu acentuada elevação do potencial hídrico, conforme aumentou o teor de água. Nesse período, o teor de água das sementes aumentou de 140 a 150 g. $\mathrm{kg}^{-1}$, e o dos eixos embrionários de 140 a $170 \mathrm{~g} . \mathrm{kg}^{-1}$, enquanto o potencial hídrico dos eixos embrionários sofreu acréscimos de 3,3MPa (lote A) a 4,2MPa (lote B).

Na protrusão da raiz primária, após 30h de hidratação, o potencial hídrico dos eixos embrionários atingiu níveis de -1,85 a -1,98MPa. Egli e Tekrony (1997) constataram que, na maturidade fisiológica e na retomada do crescimento embrionário, os eixos embrionários de sementes de soja apresentaram potenciais hídricos semelhantes, próximos a 2,07MPa. Por outro lado, Saab e Obendorf (1989) verificaram que o potencial hídrico do eixo embrionário manteve valores entre -0,6 e -1,0MPa, durante grande parte da fase de desenvolvimento da semente de soja e decresceu rapidamente na maturidade fisiológica, atingindo $-2,2 \mathrm{MPa}$.

Trinta e seis horas após o início da hidratação, o potencial hídrico do eixo embrionário aumentou para -1,10 a -1,36MPa, conforme o cultivar e o lote, crescendo, a seguir, de forma mais lenta até $48 \mathrm{~h}$.

A equivalência de potenciais hídricos entre os estádios de paralisação do acúmulo dos materiais de reserva e o início de crescimento visível do eixo embrionário, permite inferir que o estado energético da água no eixo embrionário está relacionado com o desenvolvimento e a germinação da semente, conforme relatos de Egli e TeKrony (1993); Westgate (1994); Bradford (1994); Egli e TeKrony (1997) e Villela et al. (2003).

A determinação do potencial hídrico do eixo embrionário constitui parâmetro adequado para estudar o processo de germinação, independentemente do cultivar e do lote, pela associação entre o comportamento do estado da água e as fases da germinação. 

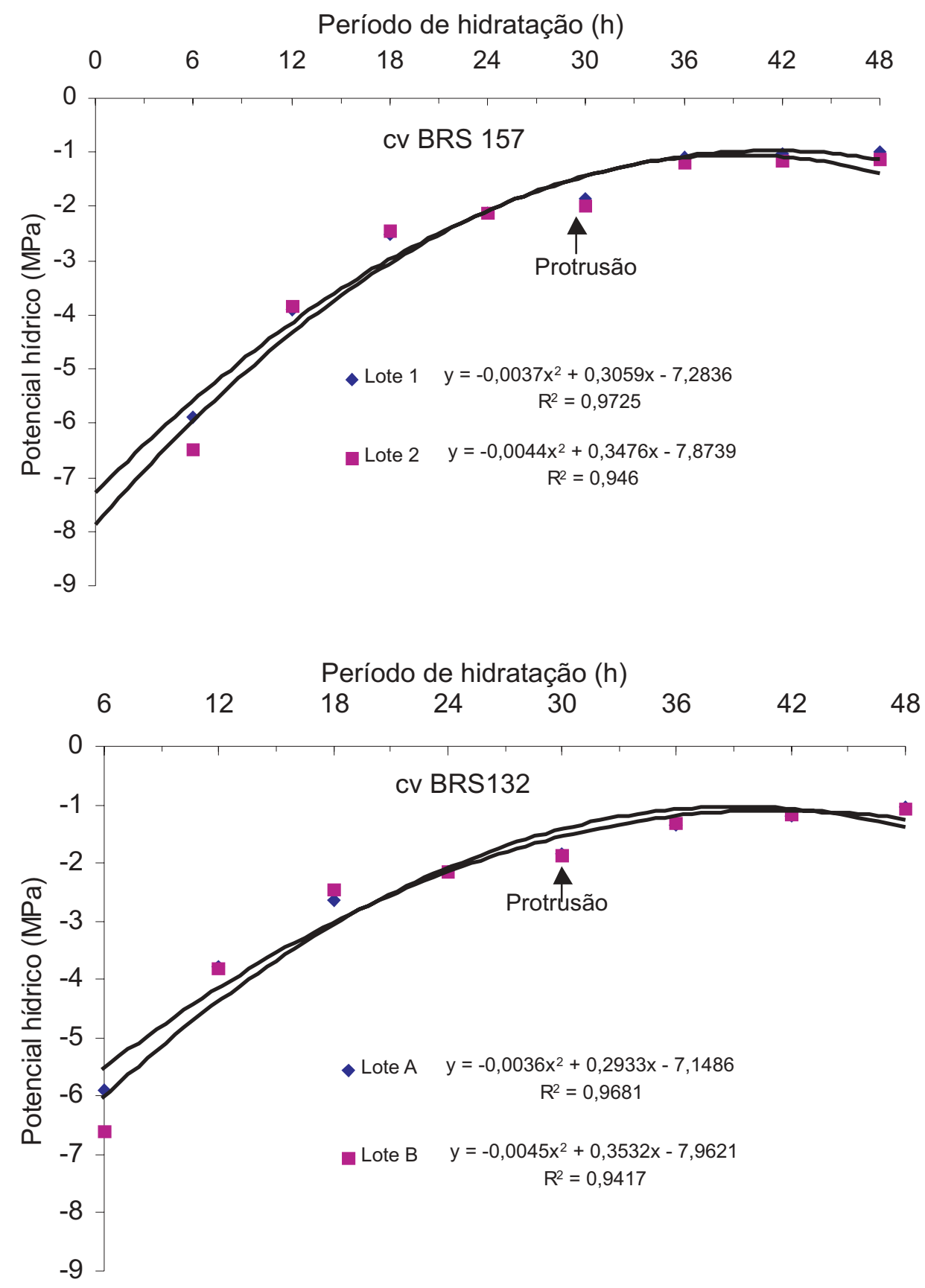

FIGURA 3. Alterações no potencial hídrico (MPa) de eixos embrionários de sementes de soja, cv BRS 157, lotes 1 e 2 e cv BRS 132, lotes A e B, durante a hidratação.

\section{CONCLUSÕES}

No momento da protrusão da raiz primária, o potencial hídrico do eixo embrionário alcança valores similares entre cultivares e lotes, indicando que o estado da água no eixo embrionário está relacionado com a germinação da semente de soja.

O eixo embrionário absorve água com velocidade superior à dos cotilédones e, além disso, atinge teores de água mais elevados durante a germinação de sementes de soja.

\section{REFERÊNCIAS}

BOYER, J.S. Measurement the water status of plants and soils. San Diego: Academic Press, 1995. 178p.

BRADFORD, K.J. Water stress and the water relations of seed 
development: a critical review. Crop Science, Madison, v.34, p.111, 1994.

BRASIL. Ministério da Agricultura. Regras para análise de sementes. Brasília: SNDA, DNDV, CLAV, 1992. 365p.

EGLI, D.B.; TEKRONY, D.M. Germination and water relations of immature soybean seed. Seed Science and Technology, Zürich, v.21, p.139-148, 1993.

EGLI, D.B.; TEKRONY, D.M. Species differences in seed water status during seed maturation and germination. Seed Science Research, Wallingford, v.7, p.3-11, 1997.

KERMODE, A.R. Regulatory mechanisms in the transition from seed development to germination: interaction between the embryo and the seed environment. In: KIGEL, Y.; GALILI, G. (Ed.) Seed development and germination. New York: Marcel Dekker, 1995. p.273-332.

LABOURIAU, L.G. A germinação das sementes. Washington: OEA, 1983. 174p.

MARCOS FILHO, J. Fisiologia de sementes de plantas cultivadas. Piracicaba: FEALQ. 2005. 495p.

McDONALD JR, M.B..; VERTUCCI, C.W.; ROOS, E.E. Soybean seed imbibition: water absorption by seed parts. Crop Science, Madison v.28, p.993-997, 1988.

ROCHA, V.S.; SEDIYAMA, T.; SILVA, R.F.; SEDIYAMA, C.S.; THIEBAUT, J.T. Embebição de água e qualidade fisiológica de sementes de soja. Revista Brasileira de Sementes, Brasília, v.6, n.2, p.51-66, 1984.

ROSSETTO, C.A.V.; NOVEMBRE, A.D.L.C.; MARCOS FILHO, J.; SILVA; W.R.; NAKAGAWA, J. Comportamento das sementes de soja durante a fase inicial do processo de germinação. Scientia Agricola, Piracicaba, v.54, n.1/2, p.106-115, 1997.

SAAB, I.N.; OBERDORF, R.L. Soybean seed water relations during in situ and in vitro growth and maturation. Plant Physiology, Bethesda, v. 89, p.610-616, 1989.

VILLELA, F.A. Water relations in seed biology. Scientia Agricola, Piracicaba, v.55, p.98-101, 1998. Número especial.

VILLELA, F.A.; DONI FILHO, L.; SEQUEIRA, E.L. Tabela de potencial osmótico em função da concentração de polietileno glicol 6000 e da temperatura. Pesquisa Agropecuária Brasileira, Brasília, v.26, n. 11/12, p.1957-1968, 1991.

VILLELA, F. A.; MARCOS-FILHO, J. Estados energéticos e tipos de água na semente. Revista Brasileira de Sementes, Brasília, v.20, n.2, p.317-321, 1998.

VILLELA, F. A.; MARCOS-FILHO, J. ; NOVEMBRE, A.D.L. C. Estado energético da água na semente de milho no processo de germinação. Revista Brasileira de Sementes, Londrina, v.25, n.1, p.95-100, 2003.

WESTGATE, M.E. Water status and development of the maize endosperm and embryo during drought. Crop Science, Madison, v.34, p.76-83, 1994. 